\title{
EFEK KOMPENSASI TERHADAP MOTIVASI KERJA GURU PADA SEKOLAH WIDYA BATAM
}

\section{COMPENSATION EFFECT ON MOTIVATION OF TEACHER WORK IN WIDYA SCHOOL BATAM}

\author{
Lutfi Erwin Lubis \\ Program Studi Manajemen, STIE Nagoya Indonesia, Indonesia \\ erwinbinlukman@gmail.com
}

\begin{abstract}
Abstrak
Tujuan dari penelitian ini adalah untuk mengetahui dan menganalisa pengaruh kompensasi terhadap motivasi kerja guru di Sekolah Widya Batam. Populasi penelitian adalah guru di Sekolah Widya Batam sebesar 137 orang guru. Ukuran sampel yang di ambil adalah sebesar 102 orang guru, dengan teknik pengambilan sampel menggunakan rumus slovin. Penelitian ini menggunakan instrumen kuesioner untuk mengukur dua variabel: kompensasi dan motivasi. Instrumen ini telah dicoba sebelum digunakan untuk mengumpulkan data, dan hasil masing-masing instrumen valid dan dapat diandalkan. Hasil penelitian ini adalah ada pengaruh langsung yang signifikan antara kompensasi terhadap motivasi. Motivasi adalah variabel terikat. Kompensasi adalah variabel bebas yang mempengaruhi Motivasi, oleh karena itu disarankan Kompensasi harus mendapat perhatian dari para pemimpin di Sekolah Widya dalam rangka meningkatkan Motivasi guru.
\end{abstract}

\section{Kata kunci: Kompensasi, Motivasi}

\begin{abstract}
The purpose of this research is to know and analyze the influence of compensation on teacher work motivation in Widya Batam School. The research population is teachers in the Widya Batam School of 137 teachers. The sample size taken was 102 teachers, with sampling technique using slovin formula. This study uses questionnaire instruments to measure two variables: compensation, and motivation. This instrument has been tried before it is used to collect data, and the results of each instrument are valid and reliable. The data analysis technique uses path analysis, which is used to test the significance of each path coefficient. The result of this research is there is significant direct influence between compensation to motivation. Motivation is the dependent variable. Compensation is an independent variable that affects Motivation, therefore it is recommended that Compensation should get the attention of leaders in the Widya School in order to increase teacher motivation.
\end{abstract}

\section{Keywords: Compensation, Motivation}

\section{PENDAHULUAN}

Kualitas SDM suatu organisasi atau perusahaan turut dipengaruhi faktor Motivasi. SDM yang mempuyai Motivasi tinggi akan berkomitmen melaksanakan tugas dan tanggung jawabnya seoptimal mungkin dalam rangka untuk memajukan organisasi tempat SDM tersebut bernaung. Dalam lembaga pendidikan sekolah, guru adalah salah satu SDM yang sangat mempengaruhi maju tidaknya lembaga pendidikan atau sekolah tersebut. Dalam hal lembaga pendidikan atau sekolah, guru yang mempunyai Motivasi Kerja yang tinggi terhadap lembaga pendidikannya, akan seoptimal mungkin melaksananakan tugas dan tanggung jawabnya sesuai dengan aturan-aturan yang ditetapkan dan digunakan dalam lembaga tersebut. 
Seorang guru tidak dapat optimal menjalankan tugas dan tanggung jawabnya jika tidak memiliki Motivasi Kerja. Seorang guru tidak dapat optimal menjalankan tugas dan tanggung jawabnya jika tidak memiliki Motivasi Kerja. Menurut Sopiah dalam Ririvega (2013 : 855) motivasi adalah keadaan di mana usaha dan kemauan keras seseorang diarahkan kepada pencapaian hasil-hasil atau tujuan tertentu.

Motivasi kerja guru merupakan daya dorong atau daya gerak yang membangkitkan dan mengarahkan perilaku guru pada suatu perbuatan atau pekerjaan. Menurut Samsudin, "Motivasi adalah proses mempengaruhi atau mendorong dari luar terhadap seseorang atau kelompok kerja agar mereka mau melaksanakan sesuatu yang telah ditetapkan" (Samsudin, 2009:281).

Dari pendapat di atas dapat disimpulkan Motivasi dapat dilihat dari sikap dan tingkah laku sehari-hari dalam menjalankan tugas dan tanggung jawab dengan cara berusaha untuk mentaati, melaksanakan dan menjalankan tugas dan tanggung jawab dengan penuh semangat.

Sekolah Widya Batam sebagai salah satu sekolah swasta di Batam yang menaungi mulai dari Sekolah Dasar (SD), Sekolah Menegah Pertama (SMP), dan Sekolah Menegah Kejuruan (SMK). Sekolah Widya Batam terdiri dari sekolah Widya 1 yang beralamat di Jodoh, sekolah Widya 2 di Tiban, sekolah Widya 3 di Batu Aji, dan sekolah Widya 4 di Bengkong.

Saat ini, manajemen sekolah Widya sedang berusaha untuk terus meningkatkan jumlah siswa masuk. Salah satu faktor yang mempengaruhi tingkat jumlah siswa suatu sekolah adalah kualitas dari sekolah itu sendiri sedangkan kualitas sekolah akan dipengaruhi oleh kualitas SDM termasuk didalamnya adalah guru. Guru yang berkualitas adalah seorang guru yang profesional, termasuk di dalamnya seorang guru yang memiliki Motivasi yang tinggi.

Motivasi kerja merupakan keadaan dalam diri seseorang yang mendorong keinginan untuk melakukan kegiatan-kegiatan secara optimal guna mencapai suatu tujuan organisasi. Tujuan pemberian motivasi adalah sebagai daya perangsang bagi guru agar bekerja dengan optimal dan dapat memberikan prestasi terbaik bagi organisasi. Motivasi kerja guru sangat penting karena akan sangat berpengaruh terhadap peningkatan kualitas kinerja guru.

Kompensasi yang diterima guru juga salah satu faktor yang perlu diperhatikan pihak manajemen sekolah untuk meningkatkan motivasi. Pengembangan atau peningkatan motivasi kerja karyawan dapat dilakukan dengan membayarkan kompensasi menurut pasar, mengandung nilai-nilai kekeluargaan dan mampu memenuhi kebutuhan karyawan tersebut (Aityan, 2011:4). Werther dan Davis mendefinisikan kompensasi sebagai apa yang diterima 
pekerja sebagai tukaran atas kontribusinya kepada organisasi (Werther dan Davis dalam Wibowo, 2012:289). Kompensasi merupakan sesuatu yang diterima karyawan sebagai pengganti kontribusi jasa mereka pada perusahaan atau organisasi. Pemberian kompensasi merupakan salah satu pelaksanaan fungsi MSDM yang berhubungan dengan semua jenis pemberian penghargaan individual sebagai pertukaran dalam melakukan tugas keorganisasian. Kompensasi merupakan biaya utama atas keahlian atau pekerjaan dan kesetiaan dalam bisnis perusahaan.

Kompensasi kerja adalah persepsi guru terhadap berbagai bentuk upah atau imbalan yang diperoleh dari hasil kerja yang digambarkan melalui dua komponen yaitu: Kompensasi langsung yang meliputi gaji, tunjangan fungsional, tunjangan hari raya, bonus pengabdian, bonus prestasi, uang transportasi makan, uang duka dan biaya pemakaman. Kompensasi tidak langsung meliputi bantuan biaya pengobatan rawat jalan dan rawat inap, dana pensiun, perumahan, beasiswa, penghargaan, formasi jabatan, dan rekreasi.

Pemberian kompensasi dari perusahaan merupakan salah satu faktor penting yang berpengaruh di dalam pemilihan untuk bekerja di sebuah organisasi. Pemberian kompensasi yang tepat bagi keinginan karyawan maupun kemampuan perusahaan, akan menciptakan hubungan kerjasama yang sehat untuk kemajuan kinerja perusahaan. Selain itu, kompensasi yang sesuai dengan keinginan karyawan atas pekerjaannya dapat memacu semangat karyawan untuk bekerja lebih baik dari waktu ke waktu, sehingga memberikan pengaruh positif bagi peningkatan hasil kerja karyawan, (Nuraini Firmandari, 2014:26)

Kompensasi yang maksimal akan mempengaruhi derajat kepuasan guru dalam melaksanakan tugas dan tanggung jawabnya. Derajat kepuasan yang semakin tinggi akan semakin meningkatkan motivasi guru dalam bekerja. Jika dikelola dengan baik, kompensasi membantu pihak sekolah untuk mencapai tujuan dalam memperoleh, memelihara, dan menjaga keberadaan dan loyalitas guru dengan optimum. Kompensasi yang maksimal juga dapat meningkatkan motivasi kerja seorang guru. Salah satu bentuk kompensasi adalah gaji yang diterima guru.

Berdasarkan Undang-undang Nomor 14 tahun 2005 tentang Guru dan Dosen, pasal 14 ayat 1, Dalam melaksanakan tugas keprofesionalan, guru berhak: a. memperoleh penghasilan di atas kebutuhan hidup minimum dan jaminan kesejahteraan social (UU RI No 14 tahun 2005 pasal 14 ayat 1). Artinya kompensasi berupa pendapatan yang sebaiknya diterima oleh seorang guru minimal jumlahnya di atas kebutuhan hidup minimum. Lebih jauh lagi dalam 
pasal 15 ayat 1 pada Undang-Undang Nomor 14 Tahun 2005 tentang Guru dan Dosen dijelaskan bahwa: Penghasilan di atas kebutuhan hidup minimum sebagaimana dimaksud dalam Pasal 14 ayat (1) huruf a meliputi gaji pokok, tunjangan yang melekat pada gaji, serta penghasilan lain berupa tunjangan profesi, tunjangan fungsional, tunjangan khusus, dan maslahat tambahan yang terkait dengan tugasnya sebagai guru yang ditetapkan dengan prinsip penghargaan atas dasar prestasi (UU RI No 14 Tahun 2005 pasal 15 ayat 1).

Secara umum kompensasi merupakan sebagian kunci pemecahan bagaimana membuat anggota organisasi berbuat sesuai dengan keinginan organisasi. Namun demikian kompensasi yang diberikan juga mempertimbangkan kemampuan organisasi atau perusahaan untuk memberikan kompensasi yang wajar sesuai dengan kontribusi yang diberikan karyawan atau pekerjanya sehingga kedua belah pihak sama-sama diuntungkan. Sistem kompensasi ini akan menjadi daya tarik bagi orang-orang yang berkualitas untuk bergabung dengan organisasi dan melakukan tindakan yang diperlukan organisasi.

\section{METODOLOGI}

Penelitian dilaksanakan pada Sekolah Widya 1, Sekolah Widya 2, Sekolah Widya 3 dan Sekolah Widya 4 di kota Batam, Kepulauan Riau. Sekolah Widya adalah salah satu sekolah swasta yang ada di kota Batam.

Dalam penilitian ini, digunakan survei dengan teknik analisis jalur (Path Analysis) bersifat kuantitatif dan merupakan kausul-komparatif, dengan tujuan untuk membuktikan hubungan sebab akibat atau hubungan antara variabel-variabel yang mempengaruhi dan dipengaruhi.

Analisis jalur merupakan teknik kuantitatif yang merupakan pengembangan dari regresi linear berganda. Teknik analisis jalur mempunyai kelebihan dibandingkan dengan regresi linear karena model analisis jalur dapat menemukan pengaruh tidak langsung dalam hubungan antar variabel melalui variabel perantara. Teknik analisis jalur memperoleh hasil yang lebih akurat, tajam dan detail (Rumengan, 2015:368).

Variable-variabel yang ada pada analisis jalur terbagi menjadi: (1) variable eksogen (exogenous variable), yakni variabel yang mempengaruhi atau menjadi penyebab dalam suatu model penelitian. Dalam analisis regresi disebut variabel-variabel bebas (independent variable). (2) variabel endogen (endogenous variable), yakni variabel yang dipengaruhi atau menjadi dampak dalam suatu model penelitian. Dalam analisis regresi disebut variabelvariabel terikat (dependent variable). (3) variabel residual (residual variable), variabel 
penganggu (error disturbance), atau variabel lain yang tidak diikutsertakan di dalam model penelitian, disimbolkan dengan e (Rumengan, Khaddafi, Milanie, 2015:418).

\section{Populasi dan Sampel Penelitian}

\section{Populasi}

Populasi adalah sekelompok orang, kejadian, sesuatu yang mempunyai karakteristik tertentu. Jika peneliti menggunakan seluruh elemen populasi menjadi data penelitian, maka disebut sensus, jika sebagian saja disebut sampel. Populasi mewakili karakteristik yang ingin didapatkan oleh penelitian tersebut (Rumengan dan Idham, 2015:140). Dalam penelitian ini yang menjadi populasi adalah seluruh tenaga pengajar atau guru Sekolah Widya 1, Sekolah Widya2. Sekolah Widya 3 dan Sekolah Widya 4, sebanyak 137 responden.

\section{Sampel}

Sampel adalah bagian dari populasi dengan karakteristik yang dianggap mewakili populasi penelitian (Rumengan dan Idham, 2015:140). Penarikan anggota dengan teknik sampling, hasilnya diharapkan dapat mewakili karakteristik anggota populasi penelitian. Penarikan anggota sampel dengan teknik sampling dengan menggunakan rumus Slovin:

$n=\frac{N}{\left(1+N \cdot e^{2}\right)}$

$\mathrm{n}=$ jumlah sampel

$\mathrm{N}=$ jumlah populasi target

$\mathrm{E}=$ batas toleransi kesalahan

Berdasarkan rumus Slovin tersebut, untuk populasi sebesar 137 orang dan margin of eror sebesar 5\%, maka:

$$
\begin{aligned}
\mathrm{N} & =137 /\left(1+137 \mathrm{X} 0.05^{2}\right) \\
& =137 /(1+0,3425) \\
& =137 / 1,3425 \\
& =102 \text { (pembulatan) }
\end{aligned}
$$

Dari hasil perhitungan di atas, maka jumlah sampel dalam penelitian ini adalah sebesar 102 responden.

\section{Teknik Pengumpulan Data}

Pengumpulan data adalah aktifitas yang menggunakan prosedur sistematis dan standar untuk memperoleh data yang diperlukan (Rumengan, 2015:321). 


\section{Jenis Data}

1. Data Primer, yaitu data yang diperoleh secara langsung dari responden melalui penyebaran angket pertanyaan terkait variabel penelitian yaitu variabel lingkungan kerja, kompensasi, motivasi kerja, dan loyalitas guru.

2. Data Sekunder, yaitu data yang didapatkan secara tidak langsung melalui media yang ada atau dokumen-dokumen tempat data tersebut tersedia.

\section{Instrumen Penelitian}

Secara umum yang dimaksud dengan instrumen adalah suatu alat yang karena memenuhi persyaratan akademis maka dapat digunakan sebagai alat untuk mengukur suatu obyek ukur atau mengumpulkan data mengenai suatu variabel. Dalam bidang penelitian, intrumen diartikan sebagai alat untuk mengumpulkan data mengenai variabel-variabel penelitian untuk kebutuhan penelitian (Rumengan, 2015:317).

Teknik pengumpulan data penelitian menggunakan teknik komunikasi tidak langsung, yaitu dengan menggunakan bantuan instrumen yang sudah dipersiapkan terlebih dahulu. Instrumen tersebut adalah angket tertutup berupa sejumlah pernyataan atau pertanyaan untuk diberikan kepada responden dengan 5 (lima) pilihan jawaban yang mengacu pada skala Likert.

Angket tertutup dalam penelitian ini menggunakan kuesioner yang berisi pertanyaanpertanyaan atau pernyataan-pernyataan yang sudah disusun penulis berdasarkan variabelvariabel yang digunakan dalam penelitian ini. Kuesioner tersebut ditujukan kepada responden untuk dijawab secara tertulis berdasarkan lima alternatif jawaban yang sudah disiapkan penulis. Kuesioner digunakan sebagai instrument pokok guna mengumpulkan sejumlah data yang relevan dengan kebutuhan penelitian. Jawaban kuesioner terdiri dari lima pilihan yaitu Sangat Setuju (SS) dengan bobot nilai 5, Setuju (S) dengan bobot nilai 4, Kurang Setuju (KS) dengan bobot nilai 3, Tidak Setuju (TS) dengan bobot nilai 2, dan Sangat Tidak Setuju (STS) dengan bobot nilai 1 .

\section{Kalibrasi Intrument}

\section{Uji Validitas}

Validitas menunjukan sejauh mana suatu alat pengukur itu mengukur apa yang ingin diukur. Sekiranya peneliti ingin mengukur kuesioner di dalam pengumpulan data penelitian, maka kuesioner yang disusunnya harus mengukur apa yang ingin diukurnya (Rumengan, 2015:338). 
Validasi menggambarkan bagaimana kuesioner pertanyaan benar-benar mampu mengukur apa yang akan diukur. Maka semakin tinggi validasi suatu test, maka alat test tersebut semakin tepat mengenai sasarannya, dikarenakan tidak disarankan untuk mengadakan uji signifikasin pada analisis item, maka teknik yang digunakan adalah korelasi item total yaitu konsistensi antara skor item secara keseluruhan, yang merupakan dasar dari korelasi pearson (product moment). Kriteria pengujian dilakukan dengan melihat tingkat signifikansi dimana jika menunjukan nilai signifikansi <0.05, maka dapat di simpulkan bahwa masing-masing indikator pertanyaan adalah valid (Ghozali dalam Asmir, 2014:49).

\section{Uji Reliabilitas}

Reliabilitas adalah indeks yang menunjukan sejauh mana suatu alat pengukur dapat dipercaya atau dapat diandalkan. Apabila suatu alat pengukur dipakai dua kali untuk mengukur gejala yang sama dan hasil pengukuran yang diperoleh relatif konsisten, maka alat pengukur tersebut reliabel, (Rumengan, 2015:341).

Reliabilitas merupakan salah satu ciri atau karakter utama instrument pengukuran yang baik. Tinggi rendah reliabilitas, secara empiris ditujukan oleh suatu angka yang disebut koefisien reliabilitas. Pengujian reliabilitas dilakukan dengan menghitung koefisien reliabilitas dengan menggunakan formulasi Cronbach Alpha. Suatu kontruk dikatakan reliabel jika memberikan nilai Cronbach Alpha > 0.6 (Ghozali dalam Asmir, 2014:50).

\section{Teknik Analisis Data}

Teknik analisis data yang digunakan dalam penelitian ini adalah analisis data kuantitatif. Pada teknik kuantitatif, data diuji dan dianalisis dengan perhitungan angka-angka, kemudian menarik kesimpulan dari pengujian tersebut. Terkait dengan penyajian data hasil penelitian digunakan statistika deskriptif.

Pada penelitian ini, teknik statistika yang digunakan adalah metode analisis jalur (path analysis), dimana koefisien jalur pada dasarnya adalah koefisien korelasi. Menurut Webley dikutip dalam Rumengan dan Idham (2015:202) analisis jalur merupakan pengembangan langsung bentuk regresi linier berganda dengan tujuan untuk memberikan estimasi tingkat kepentingan (magnitude) dan signifikansi (significance) hubungan sebab akibat hipotetikal dalam seperangkat variabel.

Proses penghitungan analisis data dalam penelitian ini menggunakan sarana bantu berupa komputer dengan program SPSS. Teknik analisis jalur memerlukan syarat data yang mempunyai tingkat pengukuran sekurang-kurangnya interval. 


\section{Uji Asumsi Klasik}

Tujuan dari pengujian asumsi klasik yaitu untuk melihat apakah analisis jalur merupakan model yang terbaik. Pada penelitian ini, akan dilakukan beberapa uji asumsi klasik terhadap model analisis jalur yang telah diolah yang meliputi uji normalitas dan uji linearitas.

\section{Uji Normalitas}

Uji normalitas bertujuan untuk mengetahui apakah distribusi sebuah data mengikuti atau mendekati normal, yakni distribusi data dengan bentuk lonceng. Data yang baik adalah data yang mempunyai pola seperti distribusi normal, yakni distribusi data tersebut tidak menceng ke kiri atau menceng ke kanan. Uji ini berguna untuk tahap awal dalam metode pemilihan analisis data (Rumengan dan Idham, 2015:189).

Pengujian normalitas dalam penelitian ini dilakukan dengan menggunakan uji Chi Square. Jika nilai Asymp. Chi-Square lebih besar dari 0.05, maka data berdistribusi normal.

\section{Uji Linearitas}

Uji linearitas bertujuan untuk mengetahui apakah dua variabel mempunyai hubungan yang linear serta signifikan. Uji linearitas dilakukan dengan software SPSS 20.

Kriteria penarikan kesimpulan pada pengujian linearitas adalah jika nilai Deviation from linearity lebih besar dari nilai significan 0.05 maka dua variabel yang diuji tersebut mempunyai hubungan yang linear.

\section{Uji Hipotesis}

Pengujian hipotesis dilakukan sebelum memberikan interpretasi hasil pengaruh variabel yang diteliti. Uji hipotesis dilakukan untuk mengetahui pengaruh secara langsung maupun bersama-sama variabel eksogen terhadap variabel endogen. Sebelum mengambil kesimpulan mengenai hubungan kausal dalam jalur, maka terlebih dahulu diuji keberartian (signifikansi) untuk setiap koefisien jalur yang telah di hitung.

Analisis Efek Kompensasi Terhadap Motivasi Kerja Hipotesis:

H0: Kompensasi Tidak Berefek atau Berpengaruh Langsung Terhadap Motivasi Kerja.

Ha: Kompensasi Berefek atau berpengaruh Langsung Terhadap Motivasi Kerja.

Kriteria Pengujian Hipotesis:

- Tolak H0 dan terima Ha jika nilai sig <0,05.

- Tolak Ha dan terima H0 jika nilai sig > 0,05. 


\section{PEMBAHASAN}

\section{Uji Instrument Penelitian}

Pengujian instrument penelitian dilakukan dengan menggunakan uji validitas dan uji reliabilitas dengan bantuan software SPSS 20. Jika menggunakan tehnik alpha dalam SPSS, untuk melihat validitas eksternal maka nilai corrected Item-Total Corelation dibandingkan dengan tabel r (Rumengan, Khaddafi, Milanie, 2015:86)

\section{Uji Validitas}

Tujuan dari uji validitas adalah untuk mengetahui sejauh mana instrumen yang digunakan dalam suatu penelitian dapat mengukur apa yang ingin diukur. Pengujian validitas ini dilakukan dengan melihat nilai sig. dari setiap pernyataan terhadap nilai totalnya. Dalam hal ini, item dinyatakan valid jika memiliki nilai sig. $<$ dari 0.05 . Adapun hasil uji validitas item kuisioner untuk masing-masing variabel adalah sebagai berikut:

1. Variabel Kompensasi

Tabel 1 Uji Validitas Variabel Kompensasi

\begin{tabular}{cccc}
\hline Korelasi & Nilai Sig. & Keterangan & Kesimpulan \\
\hline Soal 1 terhadap Total & 0,00 & $<0,05$ & Valid \\
Soal 2 terhadap Total & 0,00 & $<0,05$ & Valid \\
Soal 3 terhadap Total & 0,00 & $<0,05$ & Valid \\
Soal 4 terhadap Total & 0,00 & $<0,05$ & Valid \\
Soal 5 terhadap Total & 0,00 & $<0,05$ & Valid \\
Soal 6 terhadap Total & 0,00 & $<0,05$ & Valid \\
\hline
\end{tabular}

2. Variabel Motivasi Kerja

Tabel 2 Uji Validitas Variabel Motivasi Kerja

\begin{tabular}{cccc}
\hline Korelasi & Nilai Sig. & Keterangan & Kesimpulan \\
\hline Soal 1 terhadap Total & 0,00 & $<0,05$ & Valid \\
Soal 2 terhadap Total & 0,00 & $<0,05$ & Valid \\
Soal 3 terhadap Total & 0,00 & $<0,05$ & Valid \\
Soal 4 terhadap Total & 0,00 & $<0,05$ & Valid \\
Soal 5 terhadap Total & 0,00 & $<0,05$ & Valid \\
Soal 6 terhadap Total & 0,00 & $<0,05$ & Valid \\
\hline
\end{tabular}




\section{Uji Reliabilitas}

Tujuan dari uji reliabilitas ini adalah untuk mengetahui sejauh mana derajat kekonsistenan suatu alat ukur atau suatu instrument penelitian. Untuk mengetahui uji reliabilitas ini dapat dilakukan dengan menggunakan bantuan software SPSS 20 yaitu dengan melihat nilai Cronbach's Alpha. Suatu konstruk atau variabel dikatakan reliabel jika memberikan nilai Cronbach Alpha > 0.60 (Ghozali dalam Rumengan, 2015:344).

Tabel 3 Uji Reliabilitas Variabel Kompensasi, Motivasi

\begin{tabular}{lccc}
\hline \multicolumn{1}{c}{ Variabel } & Cronbach's Alpha & Keterangan & Kesimpulan \\
\hline Kompensasi & 0,763 & $>0,60$ & Reliabel \\
Motivasi & 0,824 & $>0,60$ & Reliabel \\
\hline
\end{tabular}

\section{Uji Persyaratan Analisis}

\section{Uji Normalitas}

Uji normalitas dilakukan melalui perhitungan Kolmogorov-Smirnov (1 sample $K S$ ). Pengujian normalitas ini dilakukan dengan tujuan untuk mengetahui apakah nilai residualnya berdistribusi normal atau tidak.

Tabel 4 One-Sample Kolmogorov-Smirnov Test

\begin{tabular}{|c|c|c|}
\hline & & Unstandardized Residual \\
\hline $\mathrm{N}$ & & 102 \\
\hline \multirow{3}{*}{ Normal Parameters ${ }^{a, b}$} & Mean & $0 \mathrm{E}-7$ \\
\hline & Std. Deviation & 2,01973491 \\
\hline & Absolute & ,113 \\
\hline \multirow[t]{2}{*}{ Most Extreme Differences } & Positive &, 113 \\
\hline & Negative &,- 105 \\
\hline Kolmogorov-Smirnov Z & & 1,139 \\
\hline Asymp. Sig. (2-tailed) & &, 150 \\
\hline
\end{tabular}

a. Test distribution is Normal.

b. Calculated from data.

Pengambilan keputusan:

Berdasarkan Tabel 4 di atas diketahui nilai Asymp.Sig. (2-tailed) adalah 0.150 lebih besar dari nilai signifikan 0.05 kesimpulannya variabel residual berdistribusi normal. 


\section{Uji Linearitas}

Uji Linearitas ini dilakukan dengan penggunaan software SPSS 20. Sebelumnya data berskala ordinal ditingkatkan terlebih dahulu menjadi skala interval dengan bantuan Method of Successive Interval (MSI)

Hasil Uji Linearitas

Tabel 5 ANOVA Table

\begin{tabular}{|c|c|c|c|c|c|c|c|}
\hline & & & $\begin{array}{l}\text { Sum of } \\
\text { Squares }\end{array}$ & $\mathrm{df}$ & $\begin{array}{l}\text { Mean } \\
\text { Square }\end{array}$ & $\mathrm{F}$ & Sig. \\
\hline & & (Combined) & 711,793 & 51 & 13,957 & 1,571 & ,056 \\
\hline & Between & Linearity & 384,684 & 1 & 384,684 & 43,301 & ,000 \\
\hline Motivasi * & Groups & Deviation from & 327,110 & 50 & 6,542 & ,736 & ,859 \\
\hline & Within Gr & & 444,199 & 50 & 8,884 & & \\
\hline & Total & & 1155,993 & 101 & & & \\
\hline
\end{tabular}

Pengambilan keputusan:

Berdasarkan Tabel 5 di atas diketahui nilai Deviation from linearity adalah 0.859 lebih besar dari nilai signifikan 0.05, kesimpulannya data dalam keadaan linear.

\section{Uji Hipotesis}

Dalam penelitian ini, digunakan analisis jalur (path analysis) untuk menguji pola hubungan yang mengungkapkan pengaruh variabel atau seperangkat variabel terhadap variabel lainnya, baik pengaruh secara langsung maupun pengaruh secara tidak langsung. Sedangkan untuk penghitungan koefisien jalur dilakukan dengan menggunakan software SPSS 20 berdasarkan data responden yang sudah ditingkatan dari skala likert menjadi skala interval.

\section{Menghitung Koefisien Jalur}

Koefisien Regresi

Tabel 6 Coefficients ${ }^{\mathrm{a}}$

\begin{tabular}{|c|c|c|c|c|c|c|}
\hline \multirow{2}{*}{\multicolumn{2}{|c|}{ Model }} & \multicolumn{2}{|c|}{ Unstandardized Coefficients } & \multirow{2}{*}{$\begin{array}{c}\text { Standardized } \\
\text { Coefficients }\end{array}$} & \multirow[t]{2}{*}{$\mathrm{t}$} & \multirow[t]{2}{*}{ Sig. } \\
\hline & & $B$ & Std. Error & & & \\
\hline \multirow{2}{*}{1} & (Constant) & 8,561 & 1,512 & & 5,662 & 000 \\
\hline & Kompensasi & 618 & ,087 &, 577 & 7,062 & 000 \\
\hline
\end{tabular}

a. Dependent Variable: Motivasi 
Berdasarkan tabel di atas diketahui bahwa nilai signifikan dari kompensasi $=0.00$ lebih kecil dari 0.05 yang berarti variabel kompensasi berpengaruh secara signifikan terhadap variabel motivasi.

Adapun untuk nilai Adjusted R-square dapat dilihat pada tabel 7 berikut:

Tabel 7 nilai Adjusted R-square

Tabel 7 Model Summary

\begin{tabular}{|c|c|c|c|c|c|c|c|c|c|}
\hline \multirow[t]{3}{*}{ Model } & \multirow[t]{3}{*}{$\mathrm{R}$} & \multirow{3}{*}{$\begin{array}{c}\mathrm{R} \\
\text { Square }\end{array}$} & \multirow{2}{*}{$\begin{array}{l}\text { Adjusted R } \\
\text { Square }\end{array}$} & \multirow{2}{*}{$\begin{array}{c}\text { Std. Error of } \\
\text { the }\end{array}$} & \multicolumn{5}{|c|}{ Change Statistics } \\
\hline & & & & & R Square & $\mathrm{F}$ & df1 & df2 & Sig. F \\
\hline & & & & Estimate & Change & Change & & & Change \\
\hline 1 &, $577^{\mathrm{a}}$ & ,333 & ,326 & 2,77725 & ,333 & 49,874 & & 10 & , \\
\hline
\end{tabular}

a. Predictors: (Constant), Kompensasi

Berdasarkan pada tabel Model summary di atas diperoleh nilai Adjusted-R adalah 0.326. sehingga dari nilai tersebut dapat ditentukan nilai koefisien jalur dengan residualnya, yaitu $e_{1}=\sqrt{(1-0.326)}=0.674$. Dengan demikian diperoleh penafsiran diagram jalur model sebagai berikut :

Hasil Penafsiran

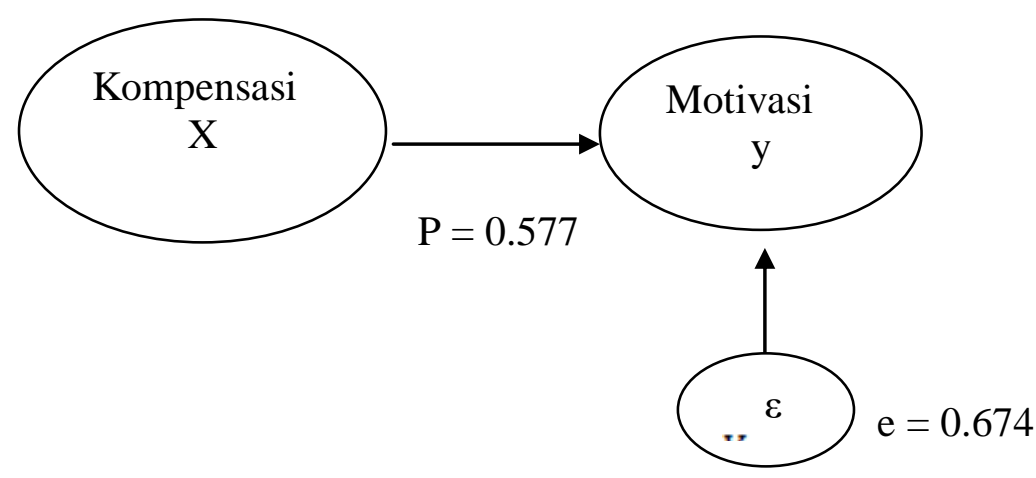

Interprestasi Analisis Jalur

Analisis Pengaruh Kompensasi terhadap Motivasi

Hipotesis :

- H0 : X tidak berpengaruh signifikan terhadap Y

- Ha : X berpengaruh signifikan terhadap Y

Kriteria Pengujian Hipotesis :

- Tolak H0 jika nilai sig $<\alpha 0.05$

- Terima H0 jika nilai sig $>\alpha 0.05$ 
Berdasarkan Tabel 7 di atas, nilai signifikan variabel kompensasi $=0.00<0.05$. maka H0 di tolak dan menerima Ha, kesimpulannya variabel kompensasi (X) berpengaruh signifikan terhadap variabel motivasi (Y).

\section{KESIMPULAN}

Berdasarkan pada rumusan masalah, hasil analisa data, pengujian hipotesis, serta pembahasan, maka diperoleh kesimpulan sebagai berikut :

1. Kompensasi di sekolah Widya secara langsung mempunyai efek yang signifikan terhadap Motivasi Kerja guru.

2. Untuk meningkatkan motivasi kerja guru di sekolah Widya, dapat dilakukan dengan cara meningkatkan kompensasi yang diterima. Hal tersebut dikarenakan adanya efek yang signifikan antara kompensasi dengan motivasi.

3. Motivasi Kerja guru pada sekolah Widya akan berimbas kepada proses belajar mengajar di kelas, sehingga turut mempengaruhi kualitas sekolah Widya itu sendiri.

\section{REFERENSI}

Aityan, S.K. dan Gupta, 2011. Challenges of Employee Loyalty in Corporate America. Journal Research Article, Accepted Version. 2 (2). pp 47-54.

Ardana, Komang, Mudiarta Utama, I Wayan, Ni Wayan Mujiati. 2012. Manajemen Sumber Daya Manusia. Yogyakarta: Graha Ilmu.

Asmir 2014. "Pengaruh Gaya kepemimpinan dan Pelatihan Terhadap Kinerja Pegawai Melalui Kepuasan Kerja pada Rumah Sakit Umum Daerah Natuna”. Tesis. Batam: Universitas Batam.

Firmandari Nuraini. 2014. "Pengaruh Kompensasi Terhadap Kinerja Karyawan Dengan Motivasi Kerja Sebagai Variabel Moderasi (Studi Pada Bank Syariah Mandiri Kantor Cabang Yogyakarta)”. Jurnal Ekonomi Dan Bisnis Islam. Vol IX No 1 Desember 2014.

Kasenda Ririvega. 2013. "Kompensasi dan Motivasi Pengaruhnya terhadap kinerja Karyawan pada PT. Bangun Wenang Beveragen Company Manado". Jurnal EMBA. Vol 1 No 3 Juni 2013.

Noor Asmirin. 2014. "Pengaruh Lingkungan Kerja Terhadap Motivasi Kerja dan Kinerja Pegawai di Satuan Kerja Unit Pelaksana Penimbangan (Jembatan Timbang) Dinas Perhubungan dan LLAJ Jawa Timur”. Jurnal Ekonomi. Vol 12 No 2, H.137-162. 
Samsudin, Sadili. 2009. Manajemen Sumber Daya Manusia. Bandung: CV. Pustaka Setia.

Samsul Arifin. 2012. Leadership, Ilmu dan Seni Kepemimpinan. Jakarta: Mitra Wacana Media

Suwardi dan Joko Utomo. 2011. "Pengaruh Motivasi Kerja, Kepuasan Kerja dan Komitmen Organisasional terhadap Kinerja Pegawai”. Jurnal Analisis Manajemen, Vol 5 No 1 Juli 2011.

Undang-Undang Republik Indonesia Nomor 14 Tahun 2005 Tentang Guru dan Dosen.

Wibowo. 2012. Manajemen Kinerja. Jakarta: PT. Rajagrafindo Persada.

Yani, 2012. Manajemen Sumber Daya Manusia. Jakarta: Mitra Wacana Media. 